Article

\title{
Skin Depigmenting Agents in Anti-Aging Cosmetics: A Medicinal Perspective on Emerging Ingredients
}

\author{
Diana I. S. P. Resende ${ }^{1,2}(\mathbb{D})$, Marta S. Ferreira ${ }^{3,4}\left(\mathbb{D}\right.$, José M. S. Lobo ${ }^{3,4}\left(\mathbb{D}\right.$, Emília Sousa ${ }^{1,2, *(\mathbb{D})}$ \\ and Isabel F. Almeida $3,4, *$ (iD
}

1 CIIMAR - Centro Interdisciplinar de Investigação Marinha e Ambiental, Avenida General Norton de Matos, S/N, 4450-208 Matosinhos, Portugal; dresende@ff.up.pt

2 Laboratório de Química Orgânica e Farmacêutica, Departamento de Ciências Químicas, Faculdade de Farmácia, R. Jorge de Viterbo Ferreira 228, 4050-313 Porto, Portugal

3 Associate Laboratory i4HB-Institute for Health and Bioeconomy, Faculty of Pharmacy, University of Porto, 4050-313 Porto, Portugal; martasbcf@gmail.com (M.S.F.); slobo@ff.up.pt (J.M.S.L.)

4 UCIBIO-Applied Molecular Biosciences Unit, MedTech, Laboratory of Pharmaceutical Technology, Department of Drug Sciences, Faculty of Pharmacy, University of Porto, 4050-313 Porto, Portugal

* Correspondence: esousa@ff.up.pt (E.S.); ifalmeida@ff.up.pt (I.F.A.); Tel.: +351-220428689 (E.S.); $+351-220428621$ (I.F.A.)

Citation: Resende, D.I.S.P.; Ferreira, M.S.; Lobo, J.M.S.; Sousa, E.; Almeida, I.F. Skin Depigmenting Agents in Anti-Aging Cosmetics: A Medicinal Perspective on Emerging Ingredients. Appl. Sci. 2022, 12, 775. https://doi.org/10.3390/app12020775

Academic Editors: Giuseppe D’Orazio and Biagia Musio

Received: 3 January 2022

Accepted: 12 January 2022

Published: 13 January 2022

Publisher's Note: MDPI stays neutral with regard to jurisdictional claims in published maps and institutional affiliations.

Copyright: (c) 2022 by the authors. Licensee MDPI, Basel, Switzerland. This article is an open access article distributed under the terms and conditions of the Creative Commons Attribution (CC BY) license (https:// creativecommons.org/licenses/by/ $4.0 /)$.
Featured Application: This analysis aims to bring insights to both formulators, involved in the development of depigmenting cosmetic products, and chemists performing the synthesis of new and existing compounds intended for this purpose.

\begin{abstract}
Human skin aging results from intrinsic and extrinsic factors. Uneven pigmentation is one of the major changes of extrinsic aging. Many compounds have been tested for depigmenting activity but only a few are actually used by the cosmetic industry, which is continually looking for new ingredients. In this study, the trends in the use of skin depigmenting ingredients in a panel of anti-aging formulations commercialized in the Portuguese pharmacy market were analyzed, by comparing the composition of the products marketed in 2011 with products launched or reformulated in 2018 (59\% and 74\%, respectively). The analysis of the top 12 ingredients put forward three novelties for 2018: tranexamic acid, bakuchiol, and 4-butylresorcinol. Regarding their mechanisms of action, tranexamic acid inhibits melanin synthesis through inhibition of the plasminogen/plasmin system. Bakuchiol depigmenting efficacy was attributed to the ability to block both $\alpha$-melanocyte-stimulating hormone and tyrosinase activation, while 4-butylresorcinol exerts its action through the inhibition of both tyrosinase and tyrosinase-related protein-1 (TRP-1). Industry-optimized and efficient synthetic methodologies that embrace green chemistry, reducing the environmental impact, are commonly used. This analysis aims to bring insights to both formulators, involved in the development of depigmenting cosmetic products, and chemists performing the synthesis of new and existing compounds intended for this purpose.
\end{abstract}

Keywords: anti-aging; pigmentation; depigmenting; tranexamic acid; bakuchiol; 4-butylresorcinol

\section{Introduction}

Skin aging is a complex biologic process that results from genetic programming —or intrinsic aging —and cumulative environmental damage—or extrinsic aging [1,2]. Together, these factors lead to structural and physiological alterations over time at variable, yet inalterable, genetically determined rates [3]. Endogenous or intrinsic aging is usually attributed to the passage of time, largely influenced by genetics, cellular metabolism, hormone, and metabolic processes, whereas exogenous or extrinsic aging is influenced by chronic exposure to sunlight, pollution, and ionizing radiation among other factors $[1,2,4,5]$. In addition to roughness, loss of elasticity, wrinkling, and pigmentary disorders can occur in 
sun-exposed areas, and they significantly impact patients' quality of life and psychological well-being [6]. The latter is usually characterized by altered melanocyte density, melanin concentration, or both, and they result in altered skin pigmentation (e.g., lentigos) [6]. Therefore, anti-aging products can contain depigmenting agents to tackle all the signs of skin aging.

Melanogenesis, the physiological process of melanin formation, is initiated by tyrosinase, a copper-dependent enzyme [7]. This enzyme plays a central role in this process, by catalyzing the first step of melanin formation. Several options, including cosmetic products, topical drugs, oral drugs, chemical peels, and light treatments are available for hyperpigmentation treatments [8]. The depigmenting effectiveness can be achieved by different action mechanisms. Hydroquinone, azelaic acid, 4-butylresorcinol, and arbutin are known tyrosinase inhibitors, thus targeting the rate-limiting step in melanin production $[9,10]$. Another approach involves the use of kojic acid and ascorbic acid (either in combination or alone) to interact with copper, an important co-factor in the melanogenesis pathway, thus inhibiting tyrosinase activity [9]. Other depigmenting agents have different mechanisms of action such as the inhibition of tyrosinase transcription (tretinoin, glucosamine, retinol, retinaldehyde, $\mathrm{N}$-acetyl glucosamine), epidermal turnover accelerant (vitamin $\mathrm{C}$, vitamin E, thioctic acid, retinoids, lactic acid, glycolic acid, salicylic acid, liquiritin, gluconolactone), inhibition of melanosome transfer (linoleic acid, niacinamide), anti-inflammatory activity (niacinamide, soy milk), and free radical scavenging agents (topical steroids, glycyrrhetinic acid, ubiquinone, bakuchiol) [7,11,12]. Cosmetic researchers have been investigating new compounds to be incorporated into anti-aging products acting on melanogenesis inhibition with greater efficacy and a suitable safety profile [13]. Cosmetic products are governed by the EU Cosmetics Regulation (Regulation (EC) No. 1223/2009). This regulation and corresponding annexes establish the safety requirements for cosmetic products and ingredients and are regularly updated. Several depigmenting agents are prohibited in cosmetic products in the EU (Annex II) while others are allowed with strict concentration limits (Annex III). As an example, hydroquinone is prohibited in cosmetics products, as it is listed in Annex II of Regulation No 1223/2009. Hence, new compounds aimed to be incorporated as skin depigmenting agents in anti-aging cosmetics should comply with this regulation in order to ensure the safety of the consumers which includes a comprehensive safety assessment. Nonetheless, studies analyzing the type of depigmenting agents and their prevalence in commercial antiaging products have not yet been performed. Insights on the cosmetic market and industry trends are valuable since this scientifically-driven industry is based on constant innovation and product development. The knowledge on which depigmenting agents are currently being used allows product differentiation, providing a wider variety between drugstore brands and high-end brands.

Hence, the aim of the present study was to characterize the usage trends of skin depigmenting agents in anti-aging cosmetics, by comparing the composition of the products marketed in 2011 with products launched or reformulated in 2018. A medicinal perspective and analysis of the current scientific evidence that supports the skin depigmenting effectiveness of the emerging ingredients was also compiled.

\section{Materials and Methods}

\subsection{Data Collection}

Data was collected from anti-aging products marketed in main stores and pharmacies in Portugal. Anti-aging cosmetics were included in the study if they exhibited on the label one of the following words: anti-wrinkle(s); anti-age/anti-aging; wrinkles repair; regenerator; aging; anti-slackening; and firming. All the information available in the product's label was collected, along with the information available on the manufacturers' websites. The data collection started in 2011 and was updated with products launched in 2018 or whose composition has been renewed that year, in order to avoid duplicate product analysis and to reflect the market trends. Cosmetics for applications on the face, neck, and 
eye contour were included, comprising more than 40 multinational brands. Following these criteria, 280 products were selected, namely 177 and 103 in 2011 and 2018, respectively.

\subsection{Data Analysis}

\subsubsection{Skin Depigmenting Ingredients Prevalence and Diversity}

The relative frequency of cosmetic products containing skindepigmenting ingredients for each year was determined. The diversity of active ingredients with a skin depigmenting effect was also assessed.

\subsubsection{Top Skin Depigmenting Ingredients}

The analysis focused on the top active ingredients with the highest usage frequency among the selected products. The usage frequency for each ingredient was expressed in percentage and the ingredients were ranked in descending order.

\subsubsection{Scientific Evidence for Skin Depigmenting Efficacy}

The evidence supporting the skin depigmenting/antiaging effect was searched on the following online databases: PubMed, Google Scholar, Scopus, Cochrane, and KOSMET.

\section{Results and Discussion}

\subsection{Prevalence Analysis of Skin Depigmenting Ingredients in Anti-Aging Products}

The preliminary analysis of the presence of skin depigmenting ingredients including 280 anti-aging cosmetics, in a total of 40 brands, indicates an increase in the use of these ingredients from 2011 to 2018 . Although in 2011 only $58.8 \%$ of the 177 anti-aging cosmetics contained this type of ingredient, a noticeable growth was observed in 2018 , where these ingredients were present in $73.8 \%$ of the new 103 studied anti-aging products, representing an increase of 25.6 percentage points in the analyzed period of time (Figure 1). Due to the widespread market value of anti-aging products, constant developments are being made to come out with new ingredients and formulations, which may have contributed to the observed market growth.

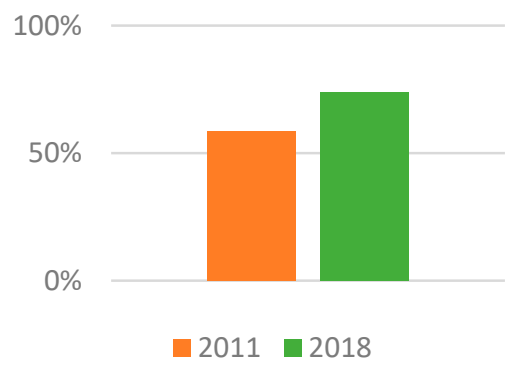

Figure 1. The prevalence of skin depigmenting ingredients in anti-aging products marketed in 2011 and 2018.

Figure 2 allows us to analyze which skin depigmenting ingredients were used in the studied anti-aging cosmetics commercialized over this seven-year span. Overall, the majority of ingredients used in these products are represented in both years. The most used ingredients in both years were alpha-hydroxy acids, ascorbic acid and derivatives, as well as retinol and derivatives. Vitis vinifera preparations are the only ingredient whose use decreased from 2011 to 2018. Noteworthy, ubiquinone was only found in 2011, and tranexamic acid together with bakuchiol and 4-butylresorcinol were only used in 2018. 


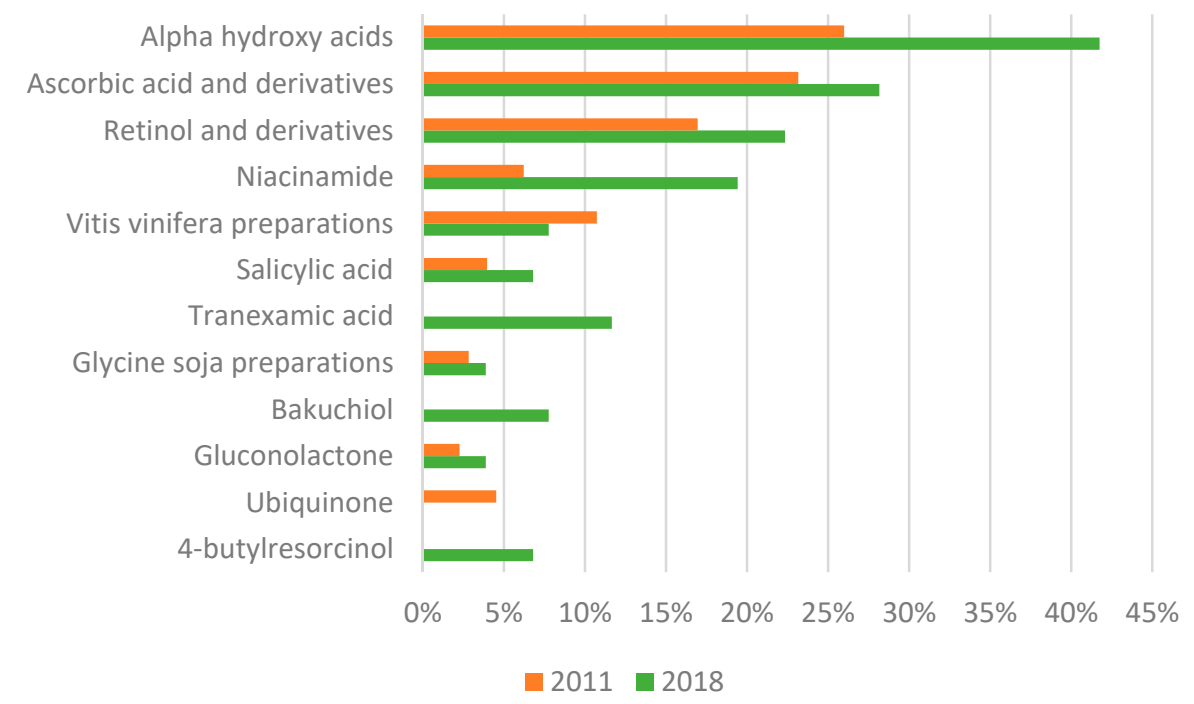

Figure 2. Top 12 skin depigmenting ingredients included in the composition of anti-aging products marketed in 2011 and 2018.

\subsection{Medicinal Chemistry Perspective of New Skin Depigmenting Ingredients in Anti-Aging Products}

After the analysis of the top 12 skin depigmenting ingredients included in the composition of the studied anti-aging products (Figure 2), we were interested in exploring the three novelties used in 2018, tranexamic acid, bakuchiol, and 4-butylresorcinol (Figure 3). Although these three ingredients are well-known, an in-depth analysis regarding their use in cosmetic products was never performed. Herein, a perspective on their mechanisms of action, analysis of the available in vitro, in vivo, and/or ex vivo studies, as well as of other randomized placebo-controlled studies including volunteers, will be discussed. Additionally, the efficacy of the available synthetic pathways will also be considered in order to provide meaningful insight toward the development of new and more effective ingredients.<smiles>NCC1CCC(C(=O)O)CC1</smiles>

Tranexamic acid

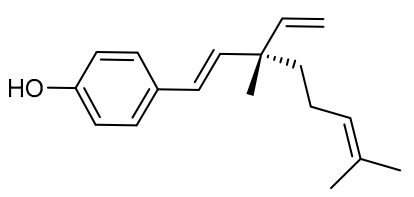

(S)-Bakuchiol<smiles>CCCCc1ccc(O)cc1O</smiles>

4-Butylresorcinol

Figure 3. Structures of tranexamic acid, (S)-bakuchiol, and 4-butylresorcinol.

\subsubsection{Tranexamic Acid}

Tranexamic acid, trans-4-(aminomethyl)cyclohexane carboxylic acid, a synthetic derivative of the amino acid lysine, was developed initially as a plasmin inhibitor for the treatment of heavy bleeding resulting from trauma, surgery, and menstruation [14,15]. Recently, tranexamic acid emerged as a new standard therapy for the treatment of melasma, a common skin condition in which brown or greyish patches of pigmentation develop [8,16-18]. A combination of the demonstrated efficacy coupled with the fact that the use of this agent is rarely associated with secondary effects, contrary to hydroquinone, rendered tranexamic acid as a new gold standard in depigmenting agents [17]. This agent inhibits melanin synthesis in melanocytes by interfering with the interaction of melanocytes and keratinocytes through inhibition of the plasminogen/plasmin system, thereby decreasing free arachidonic acid and the production of prostaglandins, which are known stimulators of tyrosinase activity $[8,14,16,17]$. Tranexamic acid has been widely incorporated into cosmetic 
formulations to be used as a skin depigmenting agent in lotions, creams, milky lotions, facial packs, and scalp care cosmetics [19].

Although studies reported that the topical application of tranexamic acid (2 and 3\%) alone was effective in treating melasma [20,21], until recently, a comparison of the effectiveness of these concentrations relative to hydroquinone towards the treatment of other hyperpigmentation disorders, such as senile hyperpigmentation, was missing [17]. Recent studies developed to assess the effectiveness of tranexamic acid as a depigmenting agent proved that it was able to reduce melanin production $[8,16,17]$. To compare the effectiveness of a tranexamic acid combination serum (with galactomyces ferment filtrate, alpha arbutin, and niacinamide) against hydroquinone as a depigmenting serum in a healthy population, Anwar et al. [17] performed a three-arm randomized controlled trial. The skin brightness and pigmentation intensity were evaluated each week for 4 weeks and all groups showed a significant improvement in skin brightness and pigmentation intensity [17], with no significant differences between the treatment groups and hydroquinone; this proved that the tranexamic acid serum ( 2 and 3\%, combined with $4 \%$ galactomyces ferment filtrate, niacinamide, and alpha-arbutin) is an effective depigmenting agent [17].

The antiangiogenic and depigmenting effects of a cosmetic formulation containing tranexamic acid and $\alpha$-arbutin were screened using an in vitro model of human cells and skin culture [16]. Quantification of melanin, tyrosinase, endothelin-1, PAR-2, vascular endothelial growth factor (VEGF), and inducible nitric oxide synthase (iNOS) was performed in human fibroblasts, keratinocytes, or melanocytes that were treated with the tested cosmetic formulation and subjected to oxidative stress by UV radiation or inflammatory stress with IL-1 $\alpha$ [16]. Additionally, a histological evaluation of fragments of human skin from elective plastic surgery, treated with the cosmetic formulation containing tranexamic acid and $\alpha$-arbutin was performed using the Fontana-Masson technique for melanin view associated with hematoxylin/eosin [16]. The obtained results pointed out a positive result in the reduction of the melanic pigmentation in the skin when using the tested formulation. The reduction of the tyrosinase activity, as well as the production of melanin, reinforces the use of this product in the prevention and treatment of melasma. The reduction in VEGF and iNOS protein synthesis in cultured dermal fibroblasts indicated a significant antiangiogenic activity and, therefore, a role in the vascular component of melasma [16]. There is also one study reporting the efficacy of a formulation containing 3\% tranexamic, $1 \%$ kojic acid, and $5 \%$ niacinamide tested for the treatment of melasma, post-inflammatory pigmentation, and hyperpigmentation in Brazilian volunteers with Fitzpatrick skin types I-IV. After 12 weeks, there was a significant improvement in skin tone and skin homogeneity with good tolerance [22]. Despite these studies, tranexamic acid's sole application for the treatment of hyperpigmentation due to skin aging is yet to be established.

Over the last decade, numerous efforts have been made to find efficient methods to synthesize tranexamic acid [23-28]. Xie et al. [28] reported a seven-step synthetic route from the readily available starting material dimethyl terephthalate $\mathbf{1}$, obtaining tranexamic acid with $99.6 \%$ purity in $59.2 \%$ overall yield (Scheme 1 ). The reported process represents an optimization regarding those previously reported methodologies since it avoids the use of toxic reagents $\left(\mathrm{CrO}_{3}, \mathrm{Cl}_{2}\right)$ and solvent $\left(\mathrm{CCl}_{4}\right)$. These have a detrimental impact on the environment and human health, and also avoid the use of expensive metal catalysts (e.g., $\mathrm{PtO}_{2}$ ) which renders the process economically nonviable and industrially unattractive [28]. The synthesis of this synthetic $\omega$-amino acid consists of a direct and efficient method for the preparation of the key intermediate methyl 4-(acetamidomethyl)benzoate (6) by one-pot hydrogenation and acylation in acetic anhydride using $\mathrm{Ni} / \mathrm{Al}_{2} \mathrm{O}_{3}$ as a catalyst [28]. 
<smiles>COC(=O)CC(O)C(=O)OC</smiles>

1<smiles>CC(=O)OC(=O)c1ccc(C(=O)O)cc1</smiles>

2

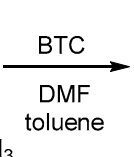<smiles>COC(=O)c1ccc(C(=O)Cl)cc1</smiles>

3<smiles>COC(=O)c1ccc(C(N)=O)cc1</smiles>

4<smiles>COC(=O)c1ccc(C#N)cc1</smiles>

\begin{tabular}{l|l}
$\mathrm{Ni}-\mathrm{Al}_{2} \mathrm{O}_{3}$ & $\mathrm{Ac}_{2} \mathrm{O}$
\end{tabular}

$\mathrm{H}_{2}(1.0 \mathrm{MPa}) \mathrm{AcONa}$

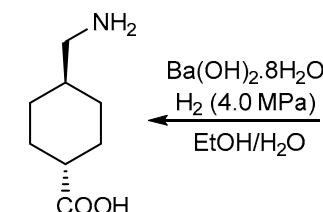

Tranexamic acid

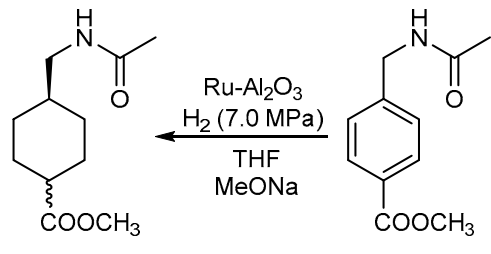

6

Scheme 1. Synthesis of tranexamic acid by Xie et al. "Reprinted (adapted) with permission from [28]. Copyright 2021 American Chemical Society".

Later, the synthesis of tranexamic acid was achieved by a new synthetic route starting from E-4-oxocyclohexane-1-carboxylate (8) using simple and commonly available reagents and under mild conditions (Scheme 2) [29]. This synthetic process was also aimed to avoid all the toxic and costly reagents and high-pressure reactions previously reported [23-27].

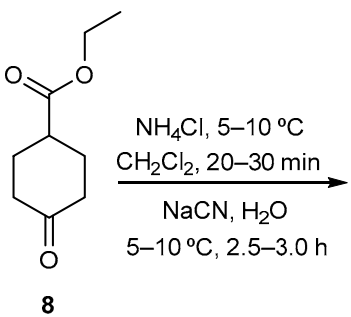<smiles>CCOC(=O)C1CCC(O)(C#N)CC1</smiles>

9

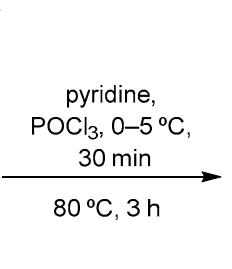<smiles>CCOC(=O)C1CC=C(C#N)CC1</smiles>

10<smiles>N#CC1=CCC(C(=O)O)CC1</smiles>

11

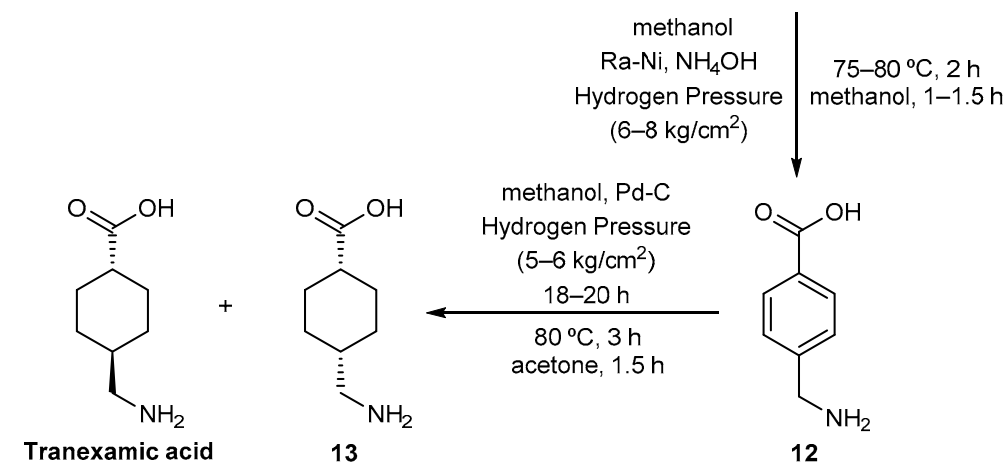

Scheme 2. Synthesis of tranexamic acid by Vanga et al. Adapted from [29].

One of the latest reports on the synthesis of this acid relates to an efficient, greener preparation process of the pure tranexamic acid in higher purity using milder conditions and reduced cycle times. This environmentally friendly procedure involves effective recycling of all the minor products and the reagents used, making the process industrially applicable and cost-effective (Scheme 3) [30]. Hence, halogenation of the starting material trans-1,4-cyclohexane dimethanol (14) and additional oxidation gives 4-bromomethyl cyclohexane-1-carboxylic acid (18). Further esterification of 18 followed by azidation, hydrolysis to the corresponding potassium salt 21, and final reduction yields tranexamic acid [30]. 

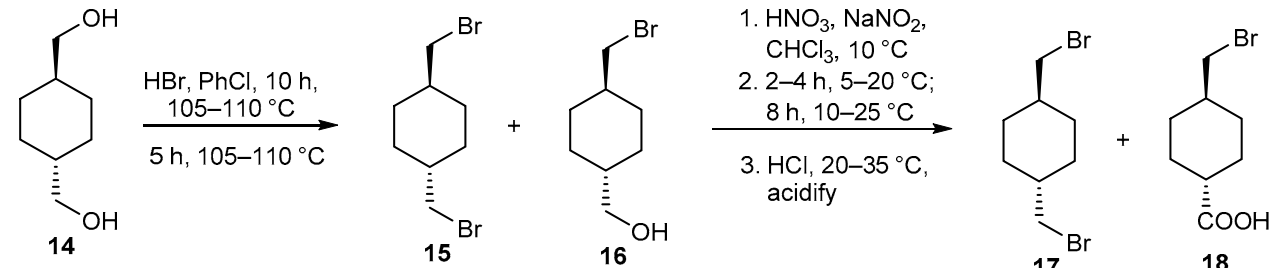

17

18

$\mathrm{H}_{2} \mathrm{SO}_{4}, \mathrm{MeOH}$,

$\mathrm{PhMe},<40^{\circ} \mathrm{C}$;

$40^{\circ} \mathrm{C} \rightarrow 70^{\circ} \mathrm{C}$ $8 \mathrm{~h}, 70^{\circ} \mathrm{C}$

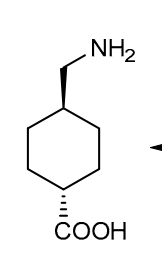

Tranexamic acid
1. Ra- $\mathrm{Ni}, \mathrm{H}_{2} \mathrm{O}, \mathrm{rt} \rightarrow 50^{\circ} \mathrm{C}$

2. $\mathrm{H}_{2}, 12 \mathrm{~h}, 45-50^{\circ} \mathrm{C}$; $50^{\circ} \mathrm{C} \rightarrow 70^{\circ} \mathrm{C} ; 2 \mathrm{~h}, 70^{\circ} \mathrm{C}$

3. $\mathrm{AcOH}, \mathrm{pH} \mathrm{6-7}$

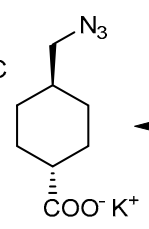

21

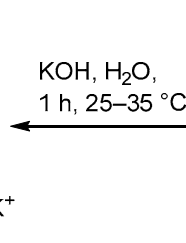

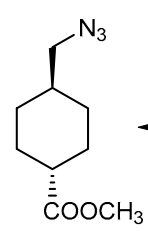

20

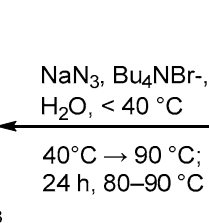

$40^{\circ} \mathrm{C} \rightarrow 90^{\circ} \mathrm{C}$;

30].

\subsubsection{Bakuchiol}

Bakuchiol is a monoterpene isolated from the seeds of Psoralea corylifolia Linn., a plant widely used in China and India to treat a variety of diseases [31]. The wide range of biological activities previously demonstrated by bakuchiol rendered this ingredient a leading candidate for drug development [31]. Bakuchiol has recently emerged as a trendy ingredient in cosmetic skincare products, claiming to have similar efficacy to over-the-counter vitamin A derivative products [32]. In fact, although no structural similarity is observed, bakuchiol has recently been recognized as a "functional analogue of retinol" [33], being in some instances even considered a "natural substitute" of retinol with less undesirable effects [34].

Although bakuchiol is currently used in cosmetic skincare products, only a few studies have been reported in early 2019 and recently reviewed proving its significant efficacy in reducing the signs of skin aging [12,32-34]. Its depigmenting efficacy was shown in two clinical studies using creams containing $0.5 \%$ bakuchiol, with good tolerability, and these findings are attributed to bakuchiol's ability to block both $\alpha$-melanocyte-stimulating hormone $(\alpha-\mathrm{MSH})$ and tyrosinase activation [12,33]. In mammals, $\alpha-\mathrm{MSH}$ is required for the development of pigmentation, by binding to its specific melanocortin-1 receptor and by increasing cyclic adenosine monophosphate. Melanogenesis is induced by strongly upregulating the expression of melanogenic enzymes such as tyrosinase. Due to the emergence of bakuchiol in the skincare market, several studies have recently been performed to highlight its relevant usage in a variety of cosmetic products beyond anti-aging products, such as formulations for sensitive skin.

A study with a bakuchiol anti-aging cleanser and moisturizer for sensitive skin examined the tolerability, efficacy, and barrier effects in subjects with sensitive skin [35]. The analyzed skincare products were well tolerated and effective in terms of visual smoothness, tactile smoothness, clarity, radiance, and overall appearance [35]. Other studies evaluated the in vitro efficacy of a serum combining bakuchiol and Vanilla tahitensis extract in the prevention of skin photoaging [36]. Results showed a good safety profile and clinical anti-aging efficacy, reducing ptosis, and increasing skin firmness and radiance. Regarding photoprotection, the combination of both ingredients demonstrated synergistic protection against IL-8 and p16 overexpression [36]. A related study developed by the same authors demonstrated a positive synergy to fight against the signs of skin aging by combining both of these ingredients [37]. The topical use of this combination was assessed in normal human dermal fibroblasts obtained from healthy donors. The treatment of fibroblasts with vanilla extract or bakuchiol, or their combination, resulted in the prevention of morphological 
changes induced by UVA exposure, indicating a potential activity of these compounds towards the prevention and/or reduction of wrinkles, to firm the skin, and/or restart epidermal and dermal cell activity [37]. Additionally, this association prevented the senescence of UVA-related cells, allowing them to revive the activity of epidermal and dermal cells [37].

A clinical study developed to assess the anti-aging efficacy and safety of a new night facial serum combining melatonin with bakuchiol and ascorbyl tetraisopalmitate in all skin types was also recently reported [38]. The efficacy, safety, and general properties of the serum were assessed in 103 subjects, and after 12 weeks of clinical evaluation, the serum showed a significant decrease in wrinkles (11\%), an increase in skin firmness $(8 \%)$, a reduction in redness (70\%), and an overall improvement in skin quality and complexion [38]. Additionally, hydration levels increased significantly and transepidermal water loss significantly decreased [38]. The serum was positively evaluated by the subjects since it was also well tolerated in all skin types including oily skin [38].

Although the synthesis of bakuchiol was largely explored before 2014 [31], recent methodologies for the efficient synthesis of this natural product are scarce. In 2016, Xiong and Zhang [39] reported a chromium-catalyzed asymmetric allylation of aldehydes with $\gamma$-disubstituted allyl halides that proved to be efficient for the synthesis of this monoterpene phenol from commercially available reagents (Scheme 4 ). The reaction of geranyl bromide (22) with 2-(4-methoxyphenyl)acetaldehyde (23) proceeded smoothly to give product 24 in good yield with $91 \%$ enantiomeric excess (ee). Afterward, conversion of 24 into dehydroxylated 25 via a two-step sequence and final demethylation of 25 with MgMeI furnished the natural product (S)-bakuchiol.

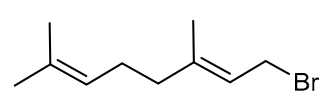

22

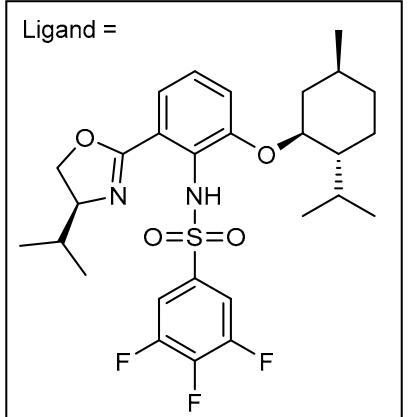<smiles>COc1ccc(CC=O)cc1</smiles>

23<smiles>C=C[C@](C)(/C=C/c1ccc(O)cc1)CCC=C(C)C</smiles>

(S)-Bakuchiol

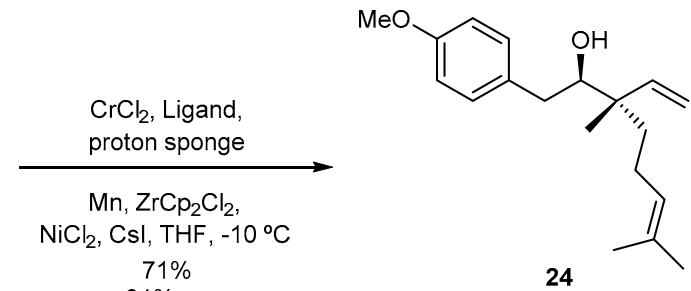

1) $\mathrm{MsCl}$, Pyridine 2) ${ }^{t} \mathrm{BuOK}, \mathrm{DMSO}$ $91 \%$ two steps<smiles>C=C[C@](C)(/C=C/c1ccc(OC)cc1)CCC=C(C)C</smiles>
25

Scheme 4. Synthesis of (S)-bakuchiol by Xiong and Zhang. "Reprinted (adapted) with permission from [39]. Copyright 2021 American Chemical Society".

(S)-Bakuchiol was also synthesized by Ozaki and co-workers [40] via an allylic substitution of secondary allylic picolinates and copper reagents for the construction of a quaternary carbon (Scheme 5). Sharpless asymmetric epoxidation of the racemic mixture 27, previously obtained from geraniol (7), with (D)-(-)-DIPT produced (S)-28. Transformation of the alcohol (S)-28 to picolinate $(S)-29$ and further allylic substitution with the required copper reagent (prepared from $4-\mathrm{MeOC}_{6} \mathrm{H}_{4} \mathrm{MgBr}$ and $\mathrm{Cu}(\mathrm{acac})_{2}$ ) proceeded smoothly to give 30 . Epoxidation of $\mathbf{3 0}$ with $m$-CPBA followed by ozonolysis to cleave the olefin part of $\mathbf{3 0}$ and reduction of the epoxide with $\mathrm{Zn}, \mathrm{NaI}$, and $\mathrm{AcOH}$ furnished aldehyde 32. A final Wittig 
reaction of the aldehyde 32 with $\mathrm{Ph}_{3} \mathrm{P}=\mathrm{CH}_{2}$ gave the known methyl ether 33 which was converted to (S)-bakuchiol [40].<smiles>CC(C)=CCC=C(C)CO</smiles>

26

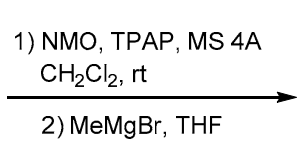

$86 \%$<smiles>CC(C)=CCC/C(C)=C/[C@H](C)O</smiles>

rac-27

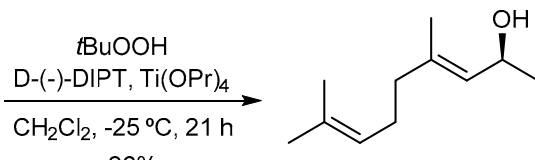

$26 \%$

(S)-28

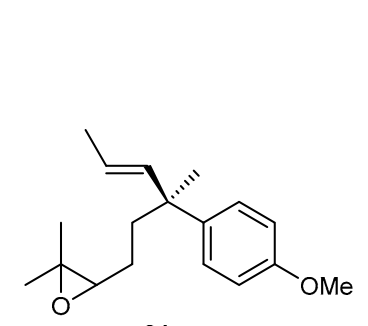

31

\begin{tabular}{r|l} 
1) $\mathrm{O}_{3}, \mathrm{CH}_{2} \mathrm{Cl}_{2}$ & 2) $\mathrm{Zn}, \mathrm{Nal}$ \\
then $\mathrm{Me}_{2} \mathrm{~S}$ & $\begin{array}{l}\mathrm{AcOH}, \mathrm{rt}, 1.5 \mathrm{~h} \\
\end{array}$
\end{tabular}

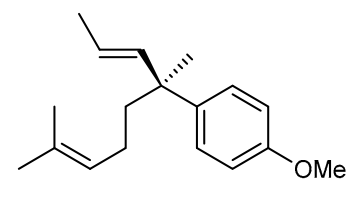

30
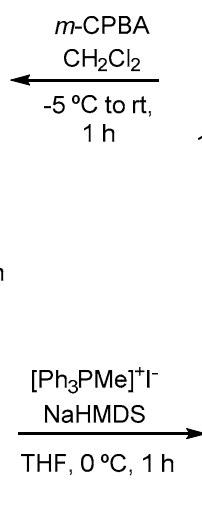

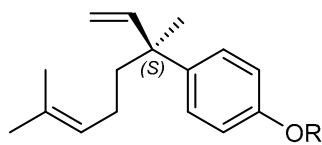

S)-33, $\mathrm{R}=\mathrm{Me}$

(S)-Bakuchiol, $\mathrm{R}=\mathrm{H}$

32

Scheme 5. Synthesis of (S)-bakuchiol by Ozaki and co-workers. Adapted from [40].

\subsubsection{4-Butylresorcinol}

4-Butylresorcinol, also known as rucinol, is a highly effective resorcinol derivative that inhibits both tyrosinase and tyrosinase-related protein-1 (TRP-1) [10]. Although knowledge of the hypopigmenting properties of this agent dates back to 1995 [41], several in vitro and in vivo studies have documented its efficacy and action over the last years [10]. In fact, in vitro assays on the inhibition of human tyrosinase activity have revealed the superiority of 4-butylresorcinol when compared to kojic acid, hydroquinone, and arbutin [42]. A study aimed at providing a convenient screening method to differentiate phenolic skin tyrosinase inhibitors from leukoderma-inducing phenols concluded that leukoderma-inducing phenols (rhododendrol, raspberry ketone, 4-methoxyphenol, 4-benzyloxyphenol, 4-tert-butylphenol, and 4-tert-butylcatechol) were readily oxidized by mushroom tyrosinase to form ortho-quinones while phenolic skin tyrosinase inhibitors (ellagic acid, 4- $n$-butylresorcinol, potassium 4-methoxysalicylate, and 2,20-dihydroxy-5,50di-n-propylbiphenyl) were not oxidized by mushroom tyrosinase, while arbutin was only slowly oxidized [43]. This study highlighted that there is a necessity that tyrosinase inhibitors should also be examined as substrates if they are phenolic compounds since leukoderma-inducing phenols are readily oxidized by tyrosinase to form reactive orthoquinone species [43].

The superiority of 4-butylresorcinol over other depigmenting agents is translated in the number of patents approved over the last years reporting studies on cosmetic formulations containing this agent. As an example, in the year 2021, at least 14 patents were approved related to the incorporation of 4-butylresorcinol in a composition of a depigmenting cream [44-57].

A pilot clinical study aimed at evaluating the efficacy and safety of a skin depigmenting serum applied twice daily combined with a spot-preventing SPF50+ sunscreen in healthy female subjects with melasma hyperpigmentation was recently reported [58]. The studied serum contained niacinamide, hydroxyphenoxy propionic acid, dipotassium glycyrrhizate, 
glycolic acid, and 4- $n$-butylresorcinol, and was applied twice a day combined with a spotpreventing SPF50+ sunscreen for treatment of melasma [58]. The skin depigmenting serum has shown a rapid clinical efficacy in reducing melasma hyperpigmentation in adult women, with good tolerability. However, randomized and controlled studies with a large sample size need to be performed in order to validate this experiment [58]. Another interesting study was developed by Mohan et al. towards the assessment of efficacy, safety, and tolerability of $4-n$-butylresorcinol $0.3 \%$ cream [10]. This study was aimed at evaluating the use of a $0.3 \% 4-n$-butylresorcinol cream instead of the widely studied, and available in the literature, $0.1 \%$ cream in Indian skin, which is more prone to irritation with hypopigmenting agents. This study explored the efficacy, safety, and tolerability of $4-n$-butylresorcinol $0.3 \%$ cream in fifty-two Indian subjects (90.38\% females, mean age of patients: $38.5 \pm 7.8$ years) with melasma. The treatment was well tolerated by all the study subjects with a twice a day application of $4-n$-butylresorcinol $0.3 \%$ cream for 8 weeks over the areas of melasma. Since no adverse reactions were reported throughout the study period, it was possible to conclude that $4-n$-butylresorcinol $0.3 \%$ cream is safe, effective, and well tolerated in Indian patients with melasma [10]. Noteworthy, although this ingredient has been used in several anti-aging cosmetic products in 2018, only two clinical studies demonstrating its efficacy for aging-induced pigmentation have been found [59]. Volunteers with senile hyperpigmentation on the forearm were treated twice daily with a formula containing $0.3 \%$ $4-n$-butylresorcinol, $0.5 \%$ phenylethylresorcinol, or a vehicle. After eight weeks, the $4-n-$ butylresorcinol formula significantly reduced senile hyperpigmentation intensity, measured by spectrometry and digital photography, contrary to both $0.5 \%$ phenylethylresorcinol and the vehicle control. Further improvements were assessed after 12 weeks. Grippaudo et al. reported the effects of the application of three cosmetic products containing 4butylresorcinol and glycyrrhetinic acid for 4 weeks, with or without a previous fractional laser photothermolysis, for lightening hand solar lentigines [60]. The 4-butylresorcinol and glycyrrhetinic acid skincare regimen were well tolerated and efficacious at reducing solar lentigo colors and dimensions measured by dermatoscopic imaging, both for the treatment and control groups. There were no significant differences when fractional laser photothermolysis was performed after product application. Recently, another resorcinol derivative named thiamidiol (isobutylamido thiazolyl resorcinol) was synthesized, showing a greater efficacy over 4-butylresorcinol [13]. This compound has shown positive results for the treatment of UVB-induced hyperpigmentation [61,62]. However, being a proprietary ingredient, it is not predictable thiamidiol will replace 4-butylresorcinol in the near future.

Several patents have also been granted for methodologies for the industrial preparation of 4-butylresorcinol since 2018 [63-68]. The large majority of these procedures comprise only a few steps, use resorcinol (34) as a raw material, and vary mainly on the secondary building block, always with the aim of significantly improving the yield, to reduce the use of accessory substances and reduce production costs [63-66,69]. Method A (Scheme 6) discloses a multi-step procedure for preparing 4-butylresorcinol which comprises the initial addition of resorcinol (34) to $N, N$-dimethylformamide with phosphorus oxychloride to obtain 2,4-dihydroxybenzaldehyde (35). Condensation with acetone under alkaline conditions to obtain 2,4-dihydroxybenzylideneacetone (36) and hydrogenation under acidic conditions gives 4-butylresorcinol. The main advantage of this methodology is the environmentally-friendly character due to the reduced generation of high-toxicity wastes [65]. Another methodology for preparing 4-butylresorcinol by a one-pot method comprises a reaction of resorcinol (34) with $n$-butyl alcohol to obtain intermediate monophenolate (Method B, Scheme 6). Then, reaction with a Lewis acid in a one-pot dehydration to obtain a crude product after acidolysis and recrystallization produces 4-butylresorcinol. The advantages of this procedure include mild conditions, low cost, and high yield and purity [66]. Three different methodologies were reported for the acylation of resorcinol (34) with aliphatic acid (38) to afford the corresponding acylated resorcin. A further reduction to 4-butylresorcinol can be achieved using (1) a triethylsilane/trifluoroacetic acid system (Method C, Scheme 6) [64], (2) hydrogen to avoid the use of a zinc amalgam (Method D, 
Scheme 6) [63], or (3) zinc dust in the presence of concentrated hydrochloric acid (Method E, Scheme 6) [69].<smiles>Oc1ccccc1</smiles><smiles>Oc1cccc(O)c1</smiles>

34<smiles>[3H]C(C)=O</smiles>

$\mathrm{NaOH}, \mathrm{H}_{2} \mathrm{O}, \mathrm{rt} ;<10^{\circ} \mathrm{C}$; $10 \mathrm{~h}, 35^{\circ} \mathrm{C} ; 0-5^{\circ} \mathrm{C}$

2. $\mathrm{HCl}, \mathrm{H}_{2} \mathrm{O}, \mathrm{pH} 1-3$

\section{Method B}

1. $\mathrm{KOH}, \mathrm{PhMe}, 10^{\circ} \mathrm{C} ; 10-15^{\circ} \mathrm{C}$

$$
\widehat{\mathrm{OH}}
$$

37

2. $\mathrm{ZnCl}_{2}, \mathrm{BPh}_{3}, 1 \mathrm{~h}, 40-45^{\circ} \mathrm{C}$;

3. $\mathrm{H}_{2} \mathrm{O}, 98^{\circ} \mathrm{C} ; 98^{\circ} \mathrm{C} \rightarrow \mathrm{rt}$

4. $\mathrm{H}_{2} \mathrm{SO}_{4}, \mathrm{H}_{2} \mathrm{O}$, rt, $\mathrm{pH} 1-2$<smiles>CC(=O)/C=C/c1ccc(O)cc1O</smiles>

$\mathrm{HCl}, \mathrm{H}_{2}, \mathrm{Pd}$, $\mathrm{H}_{2} \mathrm{O}, \mathrm{EtOH}$, $10 \mathrm{~h}, \mathrm{rt} \rightarrow 90^{\circ} \mathrm{C}$, $5 \mathrm{MPa}$

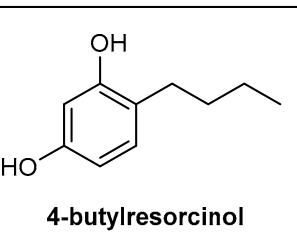<smiles>CCCCCCC(=O)O</smiles>

Method C

1. $\mathrm{ZnCl}_{2}$, rt $\rightarrow 100^{\circ} \mathrm{C} ; 2 . \mathrm{F}_{3} \mathrm{CCO}_{2} \mathrm{H}, \mathrm{Et}_{3} \mathrm{SiH}, \mathrm{rt} \rightarrow 0^{\circ} \mathrm{C}$; $0^{\circ} \mathrm{C} ; 0^{\circ} \mathrm{C} \rightarrow 60^{\circ} \mathrm{C}$; overnight, $60^{\circ} \mathrm{C} ; 3 . \mathrm{H}_{2} \mathrm{O}$

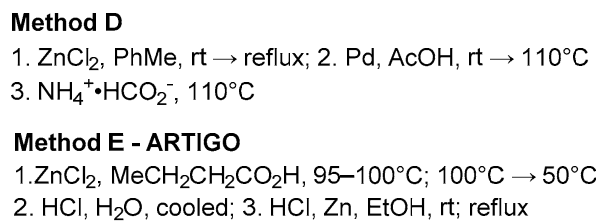

Scheme 6. Synthesis of 4-butylresorcinol from resorcinol. Adapted from [63-66,69].

Other methodologies towards the preparation of 4-butylresorcinol include the use of different starting materials. As an example, a method that involves microchannel plates for the reduction of the carbonyl group of 2', 4'-dihydroxybutyrophenone (44) using $\mathrm{NaBH}_{4}$ and Raney Nickel as reducing agents was recently reported (Scheme 7) [67]. The overall production has a low catalyst cost, mild reaction conditions, slowly released hydrogen gas, simple operational procedures, and high yields [67]. Another procedure reports the bisO-benzylation of 2,4-dihydroxybenzaldehyde (39) with benzyl chloride (40) being carried out under alkaline conditions to obtain 2,4-dibenzyloxy benzaldehyde (41) (Scheme 7) [68]. A further Wittig reaction with a triphenylphosphine halide as a reagent, metal catalytic hydrogenation, alkenyl reduction, and debenzylation produces 4-butylresorcinol. This methodology avoids the use of excessively polluting reagents such as excessive zinc chloride and hydrochloric acid and greatly reduces the formation of wastes; additionally, the catalyst can be reused and has no by-products [68]. 


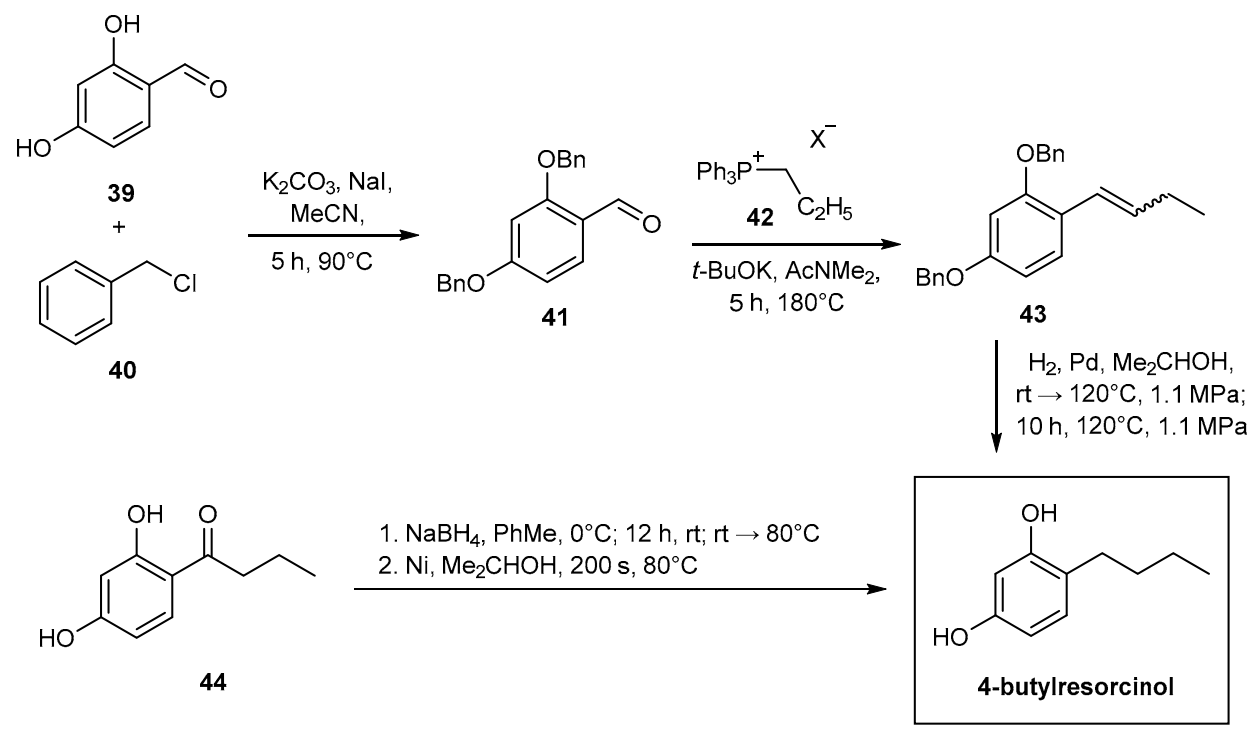

Scheme 7. Synthesis of 4-butylresorcinol. Adapted from $[67,68]$.

\section{Conclusions}

Being the most visible and exposed organ of the human body, skin reflects the aging process in humans promoted by environmental factors besides exhibiting signs of chronological aging. These changes manifest through wrinkles, loss of firmness, and hyperpigmentation. Research and development of new anti-aging formulations started to focus on tackling the signs of chronological and photoaging, including skin hyperpigmentation. The active ingredients that lighten skin tone can either be natural or synthetic substances, and they may act at different levels of the melanogenesis process. The safety concern raised around depigmenting drugs such as hydroquinone and corticosteroids led to the search for alternative ingredients for cosmetic products, including the exploitation of previously used agents, since introducing a new ingredient can be a costly and time-consuming process. To date, the trends in the use of depigmenting agents in anti-aging cosmetics have not yet been unveiled. This study reports an increasing trend in the use of these ingredients, raising up to $74 \%$ in 2018. Although the top 12 presents several well-known depigmenting agents, this work focused on highlighting the novelties introduced in 2018. Alpha-hydroxy acids, niacinamide, ascorbic acid and derivatives, as well as retinol and derivatives have great popularity as depigmenting ingredients in anti-aging cosmetics and were consistently the most used throughout the period of analysis. Tranexamic acid, bakuchiol, and 4-butylresorcinol were only found in products launched or reformulated in 2018. The clinical studies proving the efficacy of these three ingredients in the reduction of senile hyperpigmentation are usually focused on the exploitation of mixtures containing several ingredients, which hinders the attribution of the studied effect to a specific ingredient. Studies reporting their mechanisms of action are well established; however, comparative studies concerning their depigmenting efficacy would be useful to highlight the most potent ingredients.

Regarding their synthetic methodologies, advances in green processes were noted among their industrial production. Despite the three analyzed ingredients not being new ingredients, over the last few years, an upsurge was noticed in both reported methodologies for their synthesis at an industrial scale and in their incorporation into anti-aging cosmetics.

Author Contributions: Conceptualization: I.F.A.; Data collection: M.S.F.; Data analysis: D.I.S.P.R.; Writing—original draft preparation and final manuscript: D.I.S.P.R. and M.S.F.; Supervision: J.M.S.L.; Writing-review and editing: I.F.A. and E.S. All authors have read and agreed to the published version of the manuscript. 
Funding: This work is financed by national funds from FCT—Fundação para a Ciência e a Tecnologia, I.P., in the scope of the project UIDP/04378/2020 and UIDB/04378/2020 of the Research Unit on Applied Molecular Biosciences-UCIBIO and the project LA/P/0140/2020 of the Associate Laboratory Institute for Health and Bioeconomy-i4HB. This research was also supported by national funds through FCT (Foundation for Science and Technology) within the scope of UIDB/04423/2020, UIDP/04423/2020 (Group of Natural Products and Medicinal Chemistry-CIIMAR), as well as a structured program of R\&D\&I ATLANTIDA (NORTE-01-0145-FEDER-000040), supported by NORTE2020, through ERDF, and CHIRALBIO ACTIVE-PI-3RL-IINFACTS-2019.

Institutional Review Board Statement: Not applicable.

Informed Consent Statement: Not applicable.

Data Availability Statement: Not applicable.

Conflicts of Interest: The authors declare no conflict of interest.

\section{References}

1. Ganceviciene, R.; Liakou, A.I.; Theodoridis, A.; Makrantonaki, E.; Zouboulis, C.C. Skin anti-aging strategies. Dermatoendocrinology 2012, 4, 308-319. [CrossRef]

2. Tobin, D.J. Introduction to skin aging. J. Tissue Viability 2017, 26, 37-46. [CrossRef]

3. Zhang, S.; Duan, E. Fighting against Skin Aging:The Way from Bench to Bedside. Cell Transplant. 2018, 27, 729-738. [CrossRef]

4. Resende, D.I.S.P.; Ferreira, M.; Magalhães, C.; Sousa Lobo, J.M.; Sousa, E.; Almeida, I.F. Trends in the use of marine ingredients in anti-aging cosmetics. Algal Res. 2021, 55, 102273. [CrossRef]

5. Ferreira, M.S.; Magalhães, M.C.; Oliveira, R.; Sousa-Lobo, J.M.; Almeida, I.F. Trends in the Use of Botanicals in Anti-Aging Cosmetics. Molecules 2021, 26, 3584. [CrossRef]

6. Nicolaidou, E.; Katsambas, A.D. Pigmentation disorders: Hyperpigmentation and hypopigmentation. Clin. Dermatol. 2014, 32, 66-72. [CrossRef] [PubMed]

7. Opperman, L.; De Kock, M.; Klaasen, J.; Rahiman, F. Tyrosinase and Melanogenesis Inhibition by Indigenous African Plants: A Review. Cosmetics 2020, 7, 60. [CrossRef]

8. Zhao, H.; Li, M.; Zhang, X.; Li, L.; Yan, Y.; Wang, B. Comparing the efficacy of Myjet-assisted tranexamic acid and vitamin C in treating melasma: A split-face controlled trial. J. Cosmet. Dermatol. 2020, 19, 47-54. [CrossRef] [PubMed]

9. Pillaiyar, T.; Namasivayam, V.; Manickam, M.; Jung, S.-H. Inhibitors of Melanogenesis: An Updated Review. J. Med. Chem. 2018, 61, 7395-7418. [CrossRef]

10. Mohan, M.; Gowda, A.; Jaiswal, A.K.; Kumar, B.S.; Shree, S.; Gangaboraiah, B.; Shamanna, M. Assessment of efficacy, safety, and tolerability of 4-n-butylresorcinol 0.3\% cream: An Indian multicentric study on melasma. Clin. Cosmet. Investig. Dermatol. 2016, 9 , 21-27. [CrossRef]

11. Couteau, C.; Coiffard, L. Overview of Skin Whitening Agents: Drugs and Cosmetic Products. Cosmetics 2016, 3, 27. [CrossRef]

12. Dhaliwal, S.; Rybak, I.; Ellis, S.R.; Notay, M.; Trivedi, M.; Burney, W.; Vaughn, A.R.; Nguyen, M.; Reiter, P.; Bosanac, S.; et al. Prospective, randomized, double-blind assessment of topical bakuchiol and retinol for facial photoageing. Br. J. Dermatol. 2019, 180, 289-296. [CrossRef] [PubMed]

13. Mann, T.; Gerwat, W.; Batzer, J.; Eggers, K.; Scherner, C.; Wenck, H.; Stab, F.; Hearing, V.J.; Rohm, K.H.; Kolbe, L. Inhibition of Human Tyrosinase Requires Molecular Motifs Distinctively Different from Mushroom Tyrosinase. J. Invest. Dermatol. 2018, 138, 1601-1608. [CrossRef] [PubMed]

14. Huang, M.H.; Lu, Y.Y.; Lin, Y.S. Towards Boosting Power by Encapsulating Tranexamic Acid into Emulsified Particles. J. Chem. 2018, 2018, 8101540. [CrossRef]

15. Cho, Y.H.; Park, J.E.; Lim, D.S.; Lee, J.S. Tranexamic acid inhibits melanogenesis by activating the autophagy system in cultured melanoma cells. J. Dermatol. Sci. 2017, 88, 96-102. [CrossRef] [PubMed]

16. Pereira, A.F.C.; Igarashi, M.H.; Mercuri, M.; Pereira, A.F.; Pinheiro, A.L.T.A.; da Silva, M.S.; Facchini, G.; Eberlin, S. Whitening effects of cosmetic formulation in the vascular component of skin pigmentation. J. Cosmet. Dermatol. 2020, 19, 154-160. [CrossRef] [PubMed]

17. Anwar, A.I.; Wahab, S.; Widita, W.; Nurdin, A.R.; Budhiani, S.; Seweng, A. Randomized control trial outcomes of tranexamic acid combination serum as a depigmenting agent for the use in healthy individuals. Dermatol. Ther. 2019, 32. [CrossRef]

18. Perper, M.; Eber, A.E.; Fayne, R.; Verne, S.H.; Magno, R.J.; Cervantes, J.; Alharbi, M.; Alomair, I.; Alfuraih, A.; Nouri, K. Tranexamic Acid in the Treatment of Melasma: A Review of the Literature. Am. J. Clin. Dermatol. 2017, 18, 373-381. [CrossRef]

19. Shih, Y.; Wu, K.L.; Sue, J.W.; Kumar, A.S.; Zen, J.M. Determination of tranexamic acid in cosmetic products by high-performance liquid chromatography coupled with barrel plating nickel electrode. J. Pharm. Biomed. Anal. 2008, 48, 1446-1450. [CrossRef]

20. Ebrahimi, B.; Naeini, F.F. Topical tranexamic acid as a promising treatment for melasma. J. Res. Med. Sci. $2014,19,753-757$.

21. Chung, J.Y.; Lee, J.H.; Lee, J.H. Topical tranexamic acid as an adjuvant treatment in melasma: Side-by-side comparison clinical study. J. Dermatol. Treat. 2016, 27, 373-377. [CrossRef] 
22. Desai, S.; Ayres, E.; Bak, H.; Manco, M.; Lynch, S.; Raab, S.; Du, A.; Green, D.; Skobowiat, C.; Wangari-Talbot, J.; et al. Effect of a Tranexamic Acid, Kojic Acid, and Niacinamide Containing Serum on Facial Dyschromia: A Clinical Evaluation. J. Drugs Dermatol. 2019, 18, 454-459.

23. Jiang, Z.L. Preparation Method of 4-Chloromethyl Benzoic Acid t-Butyl Ester. CN Patent 1907948A, 30 December 2019.

24. Tao, X.; Wang, Z.; Wu, J.G.; Dong, D.P. Method for Preparing Tranexamic Acid from Para-Aminomethylbenzoic Acid by Catalytic Hydrogenation. CN Patent 102276490A, 19 March 2014.

25. Chang, J. Novel Technology for Synthesis of Aminomethylbenzoic Acid. CN Patent 102718673A, 15 January 2014.

26. Sun, J.L. Observation of Curative Effect of Lipoic Acid in the Treatment of Diabetic Peripheral Neuropathy. China Prac. Med. 2011, 6,160-161. Available online: http://caod.oriprobe.com/articles/26286946/__liu_xin_suan_zhi_liao_tang_niao_bing_zhou_ wei_shen_jing_bing_bian_l.htm (accessed on 3 January 2022).

27. Jiang, Z.X.; Song, Z.F.; Diao, W.R. Application of Urotropine as Catalyst in Aminomethylbenzoic Acid Synthesis. CN Patent 102816077A, 12 December 2012.

28. Li, Z.; Fang, L.; Wang, J.; Dong, L.; Guo, Y.; Xie, Y. An Improved and Practical Synthesis of Tranexamic Acid. Org. Process Res. Dev. 2015, 19, 444-448. [CrossRef]

29. Dodda, M.R.; Gunnam, C.R.; Yadharam, S.R.; Vanga, M.R. A new synthetic process for tranexamic acid from ethyl 4-oxocyclohexane carboxylate. Pharma Chem. 2016, 8, 269-274.

30. Kalpattu Kuppuswamy, B.; Kuppuswamy, V.; Mariadas, A.S.; Ganapathi, V. Greener Process for the Preparation Tranexamic Acid Including a One-Pot Process. WO Patent 2021111475A1, 10 June 2021.

31. Huang, S.; Huang, M.; Jia, X.; Hong, R. Chemistry and Biology of Bakuchiol. Chin. J. Org. Chem. 2014, 34, 2412-2423. [CrossRef]

32. Spierings, N.M.K. Cosmetic commentary: Is bakuchiol the new "skincare hero"? J. Cosmet. Dermatol. 2020, 19, 3208-3209. [CrossRef] [PubMed]

33. Chaudhuri, R.K.; Bojanowski, K. Bakuchiol: A retinol-like functional compound revealed by gene expression profiling and clinically proven to have anti-aging effects. Int. J. Cosmet. Sci. 2014, 36, 221-230. [CrossRef] [PubMed]

34. Jafernik, K.; Halina, E.; Szopa, A.; Ercisli, S. Characteristics of bakuchiol-the compound with high biological activity and the main source of its acquisition-Cullen corylifolium (L.) Medik. Nat. Prod. Res. 2020, 35, 5828-5842. [CrossRef] [PubMed]

35. Draelos, Z.D.; Gunt, H.; Zeichner, J.; Levy, S. Clinical Evaluation of a Nature-Based Bakuchiol Anti-Aging Moisturizer for Sensitive Skin. J. Drugs Dermatol. 2020, 19, 1181-1183. [CrossRef] [PubMed]

36. Bacqueville, D.; Maret, A.; Noizet, M.; Duprat, L.; Coutanceau, C.; Georgescu, V.; Bessou-Touya, S.; Duplan, H. Efficacy of a dermocosmetic serum combining bakuchiol and vanilla tahitensis extract to prevent skin photoaging in vitro and to improve clinical outcomes for naturally aged skin. Clin. Cosmet. Investig. Dermatol. 2020, 13, 359-370. [CrossRef]

37. Duplan, H.; Bacqueville, D.; Poigny, S. Tahiti Vanilla Extract and 4-[(1E,3S)-3-ethenyl-3,7-dimethylocta-1,6-dienyl]phenol for Controlling Skin Aging. WO Patent 2019224303A1, 28 November 2019.

38. Goldberg, D.J.; Robinson, D.M.; Granger, C. Clinical evidence of the efficacy and safety of a new 3-in-1 anti-aging topical night serum-in-oil containing melatonin, bakuchiol, and ascorbyl tetraisopalmitate: 103 females treated from 28 to 84 days. J. Cosmet. Dermatol. 2019, 18, 806-814. [CrossRef]

39. Xiong, Y.; Zhang, G. Enantioselective Synthesis of Quaternary Stereocenters via Chromium Catalysis. Org. Lett. 2016, 18, 5094-5097. [CrossRef] [PubMed]

40. Kobayashi, Y.; Sugihara, Y.; Tojo, T.; Ozaki, T. Synthesis of (S)- and (R)-sporochnol by using the allylic substitution of the secondary allylic picolinate. Heterocycles 2016, 93, 47-54. [CrossRef]

41. Okubo, T.; Oyobikawa, M.; Futaki, K.; Matsukami, M.; Fujii, A. The inhibitory effects of 4-N-butyl-resorcinol on melanogenesis. J. Dermatol. Sci. 1995, 10, 88. [CrossRef]

42. Huh, S.Y.; Shin, J.-W.; Na, J.-I.; Huh, C.-H.; Youn, S.-W.; Park, K.-C. The Efficacy and Safety of 4-n-butylresorcinol 0.1\% Cream for the Treatment of Melasma: A Randomized Controlled Split-face Trial. Ann. Dermatol. 2010, 22, 21-25. [CrossRef]

43. Ito, S.; Wakamatsu, K. A convenient screening method to differentiate phenolic skin whitening tyrosinase inhibitors from leukoderma-inducing phenols. J. Dermatol. Sci. 2015, 80, 18-24. [CrossRef]

44. Bian, F.; Si, C.; Yu, G.; Duan, T.; Li, L. Composition for Whitening and Brightening Skin. CN Patent 112957272A, 15 June 2021.

45. Chen, R.; Wu, T. Composition of Whitening Cream and Its Preparation Method. CN Patent 112933020A, 11 June 2021.

46. Goo, B. Mask, Device, and Method for Whitening Skin. U.S. Patent 20210030141A1, 4 February 2021.

47. Kong, Q.; Chen, Q.; Xia, G.; Mao, S. Composition Containing Alpha-Hydroxy Acid with Skin Whitening Effect and Preparation Method and Application Thereof. CN Patent 113576933A, 2 November 2021.

48. Li, C. Preparation Method of Composite Freckle Removing and Whitening Composition. CN Patent 112386552A, 23 February 2021.

49. Li, R.; Chen, S.; Chen, L. Whitening Skin-Care Composition Comprising 4-Butylresorcinol, Nicotinamide and Resveratrol, and Its Preparation Method. CN Patent 112675100A, 20 April 2021.

50. Luo, F.; Niu, L.; Yang, M. Whitening Composition and Preparation Method. CN Patent 112402316A, 26 February 2021.

51. Pan, J.; Pan, Y.; Liu, G.; Huang, H.; Huang, L.; Li, Y.; Qiu, S. Composite Whitening Agent Lipid Carrier Containing Cream. CN Patent 112516040A, 19 March 2021.

52. Qiu, J.; Wang, X.; Pygmalion, M.-J. Cosmetic Composition for Brightening and/or Whitening Skin Materials. WO Patent 2021114024A1, 17 June 2021.

53. Wang, M. Whitening and Freckle Removing Essence and Its Preparation Method. CN Patent 112587426A, 2 April 2021. 
54. Wang, M. Whitening and Freckle-Removing Cream and Preparation Method. CN Patent 112603869A, 6 April 2021.

55. Wang, Y.; Guo, X.; Mao, H.; Xu, S.; Wang, J. Composition Containing Tranexamic Acid and Acetylchitosamine for Improving Skin Tone for Whitening Cosmetics. CN Patent 112618400A, 9 April 2021.

56. Xie, K.; Liu, H.; Zhang, Y.; Wu, C.; Tang, R. A Transparent Whitening Essence Containing 4-butyl Resorcinol and Preparation Method Thereof. CN Patent 113081903A, 9 July 2021.

57. Zhou, Z.; Hu, G.; Li, C.; Chen, Q.; Gong, S. Whitening Agent, Whitening Oil gel Containing the Same and Preparation Method Thereof. CN Patent 112263496A, 26 January 2021.

58. Cantelli, M.; Ferrillo, M.; Fabbrocini, G.; Granger, C. An Open-Label, Investigator-Initiated, Single-Center, Prospective, Pilot Clinical Study to Evaluate the Efficacy of a Skin Whitening serum applied twice daily combined with a spot-preventing SPF50+ sunscreen in healthy female subjects with melasma hyperpigmentation. J. Cosmet. Dermatol. 2021. [CrossRef]

59. Kolbe, L.; Mann, T.; Gerwat, W.; Batzer, J.; Ahlheit, S.; Scherner, C.; Wenck, H.; Stab, F. 4-n-butylresorcinol, a highly effective tyrosinase inhibitor for the topical treatment of hyperpigmentation. J. Eur. Acad. Dermatol. Venereol. 2013,27 (Suppl. 1), 19-23. [CrossRef]

60. Grippaudo, F.R.; Di Russo, P.P. Effects of topical application of B-Resorcinol and Glycyrrhetinic acid monotherapy and in combination with fractional $\mathrm{CO}_{2}$ laser treatment for benign hand hyperpigmentation treatment. J. Cosmet. Dermatol. 2016, 15, 413-419. [CrossRef] [PubMed]

61. Vachiramon, V.; Kositkuljorn, C.; Leerunyakul, K.; Chanprapaph, K. Isobutylamido thiazolyl resorcinol for prevention of UVB-induced hyperpigmentation. J. Cosmet. Dermatol. 2021, 20, 987-992. [CrossRef] [PubMed]

62. Philipp-Dormston, W.G.; Vila Echague, A.; Perez Damonte, S.H.; Riedel, J.; Filbry, A.; Warnke, K.; Lofrano, C.; Roggenkamp, D.; Nippel, G. Thiamidol containing treatment regimens in facial hyperpigmentation: An international multi-centre approach consisting of a double-blind, controlled, split-face study and of an open-label, real-world study. Int. J. Cosmet. Sci. 2020, 42, 377-387. [CrossRef] [PubMed]

63. Xu, J.; Zha, J. Method for Preparing 4-Alkyl Resorcin. CN Patent 107805186A, 16 March 2018.

64. He, H.; Jiang, C.; Dong, H. Organic Synthesis of 4-Alkyl-Resorcinol in Solvent-Free System. CN Patent 109534961A, 2 October 2020.

65. Liu, Y.; Yan, J.; Zhang, M.; Hu, Y. Method for Preparing 4-Butyl-Resorcinol. CN Patent 110903169A, 24 March 2020.

66. Zhang, K.; Zhang, T. One-Pot Method for Preparing 4-n-Butyl Resorcinol as Cosmetic Intermediate. CN Patent 110803980A, 18 February 2020.

67. Tan, X.; Zhang, Z.; Sun, X. Synthesis Method of 4-n-Butylresorcinol by Microchannel Reaction. CN Patent 110511117A, 29 November 2019.

68. Xu, H.; Fan, P.; Qu, H.; Tao, P.; Shen, M.; Wang, P.; Ma, S.; Shu, C.; Shan, C.; Nie, W.; et al. Preparation of 4-Butylresorcinol. CN Patent 111960924A, 20 November 2020.

69. Liu, P.; Xu, X.; Chen, L.; Ma, L.; Shen, X.; Hu, L. Discovery and SAR study of hydroxyacetophenone derivatives as potent, non-steroidal farnesoid X receptor (FXR) antagonists. Bioorg. Med. Chem. 2014, 22, 1596-1607. [CrossRef] 